\title{
Parent and Professional Collaboration in the Assessment Process
}

\author{
Jane Squires ${ }^{1}$, Misti Waddell ${ }^{1}$, Kristin Funk $^{1}$ and Marisa Macy, ${ }^{2,}$ \\ ${ }^{1}$ Early Intervention Program, University of Oregon, USA \\ ${ }^{2}$ Department of Special Education, Lycoming College, USA
}

\begin{abstract}
Partnering with families to administer and interpret assessments for preschool children with disabilities is a cornerstone of effective early childhood practice. Parent-professional partnership in the assessment process encourages effective intervention practices, including targeting of appropriate goals and using strategies based on family cultural and daily practices. An assessment approach that focuses on collaborative practices between professionals and parents of young children with cognitive and other developmental delays is presented. Two strategies shown to provide a common language for parent and professional communication and facilitate cooperation between professionals and parents are described. Parent-completed developmental screening tests and parent assistance with completion of curriculum-based assessments are also discussed in the context of a tiered approach to intervention. A case study is presented to illustrate these strategies in practice.
\end{abstract}

Keywords: Families, early intervention, and assessment.

"Early childhood assessment is a flexible, collaborative decision-making process in which teams of parents and professionals repeatedly revise their judgments and reach consensus about the changing developmental, educational, medical, and behavioral healthcare needs of young children and their families." [1]

Partnering with families to administer and interpret assessments for their young preschool children is a cornerstone of effective early childhood practice. Enhanced parent-professional interactions, improved accuracy, efficiency, and cost-effectiveness have been shown to result from collaboration with families [2-7]. Including parents in the assessment process and in other programmatic avenues is essential. This collaboration is especially critical for preschool children with disabilities (i.e. from birth to school entry) and contributes positively to parental competence, including confidence about parenting abilities. These enhancements may in turn improve child socialemotional and developmental competence [8].

Parents, ${ }^{1}$ who accompany their children in a variety of places-church, synagogue, grocery store, swimming pool, often have a broad knowledge of their young child's repertoire of skills. Parents see their child telling jokes with Uncle Ben, playing house with Cousin Jasmine, and negotiating potentially stressful

*Address correspondence to this author at the Department of Special Education, Lycoming College, USA; Tel: 541-321-4383; Fax: 541-321-4389; E-mail: macy@lycoming.edu

${ }^{1}$ The term parent will be used to refer to parents and other primary caregivers in a young child's life including foster parents and grandparents. encounters with unfamiliar adults during a visit to the pediatrician's office. Together-the parents who witness their child in many different home and community settings, and the preschool teacher who observes the child interacting with peers and teachers-have a more comprehensive view of what the child can do and what his/her developmental needs are than either party does on their own. The "flexible, collaborative decision-making process" described above by Bagnato and Neisworth (1991) entails parents and professionals working together over time to assess what a child can do, her strengths and needs, and what changing demands on the child may require. When cultural perspectives and experiences of families are different from those of preschool providers, it is especially critical to include families in all phases of the assessment process and to repeatedly check in with parents to make sure the ongoing needs of the young child and family are being met.

Language and cultural appropriateness for individual children and families are critical features of valid and reliable assessment results. If an assessment does not reflect the familiar experiences and local culture of the children taking the test, their true ability and performance will not be measured $[2,9,10]$. In these instances, inclusion of parents is critical for assuring fairness and minimizing bias in the assessment process. Evidence-based practices that validate, respect, and respond to the family's needs and expectations, supporting their values, beliefs, and language are recommended [11]. Gathering complementary information such as observations across the family's daily routines in addition to family interviews are additional effective strategies for 
increasing validity of standardized test results for children from diverse cultural backgrounds [11].

\section{STANDARDS FOR PARENT-PROFESSIONAL COLLABORATIVE ASSESSMENT}

Early intervention/early childhood special education (El/ECSE) services have evolved from provision of solely teacher-directed services, including professionally administered assessments, to a more collaborative partnership model with parents and family members. The Federal Individuals with Disabilities Education Act (IDEA) passed in 1990 (P.L. 101-476) and its amendments mandate family partnerships in developing and implementing educational plans for children with disabilities. Both the Individualized Family Service Plan (IFSP) for infants and toddlers and the Individualized Education Plans (IEP) for older children call for family input in the assessment and evaluation processes.

"Best practice" standards proposed by many early childhood professionals organizations include recommendations for collaborative parent-professional assessment that builds on child and family strengths. The Division for Early Childhood (DEC) [12, 13] recommends that family members and professional jointly plan and implement child assessments as well as appropriate family-identified outcomes. The National Association for the Education of Young Children (NAEYC) [14] proposes assessment as an ongoing, strategic process in which parents and family members are considered an important source of assessment information that provide input in an ongoing way. Finally, the National Research Council [15] suggests families should be considered equal and contributing partners and play a critical role in the assessment process. Parents should be encouraged to be involved in selecting, conducting, and providing information to contextualize assessment results, including identifying discrepancies between the child's performance on a formal assessment and what the child usually does in other settings [15].

\section{FAMILY-CENTERED ASSESSMENT APPROACHES}

Developers of developmental screening assessments were perhaps the first to recognize the important role that parents can play in the assessment process of preschool children with potential disabilities and developmental delays. The Denver Prescreening Developmental Questionnaire [16] is completed by parents prior to professional administration of the
Denver Developmental Screening Test [17]. Those children with scores below their expected developmental level then proceed to the next phase, administration of the full Denver screening test. As screening is a quick snapshot of developmental skills, having parents assist in this process is both cost effective and improves the accuracy of screening results [7].

Parents have also long been involved as collaborative assessors of a child's social emotional and behavioral competence. The parent form of the Child Behavior Checklist [18] asks parents to rate their child on the presence or absence of 100 problem behaviors; parents also assist in completion of the infant/toddler Bayley Social-Emotional Adaptive Behavior Questionnaire [19] that accompanies the Bayley Scales of Infant and Toddler Development [19], the Social-Emotional Early Childhood Scale [20], and the Brief Infant-Toddler Social Emotional Assessment (BITSEA) [21], to name a few. The comprehensive and varied experiences that family members have with their child across settings and people make them uniquely positioned to provide critical information on social, emotional, and behavioral competencies and needs.

A third common approach for family-based collaborative assessment includes questionnaires that gather information from parents to augment and direct professionally administered assessments of general development, and to assist in identifying child and family goals and planning for intervention for children with cognitive and other developmental disabilities. One example is the Family Report, a component of the Assessment, Evaluation, and Programming System (AEPS) [22]. The AEPS Family Report is a familycompleted assessment form that directly corresponds to the developmental child goals on the professionally administered AEPS Child Observation Data Recording Form. The Family Report asks parents to provide information about daily routines and preferred family activities, eliciting input on how the child participates in these routines and activities, what makes that participation enjoyable or difficult for the family, and what additional skills caregivers hope to see their child develop. The Family Report also provides an opportunity for parents to assess their child's performance on selected goals-the same skills and behaviors assessed by professionals-thus engaging parents in shaping services for their child that address family needs and priorities. In order to facilitate parent involvement, the AEPS Family Report can be completed independently by parents or-in the case of 
parent preference, language differences, or literacy skills-presented by a professional in an interview format.

The Survey Form and Expanded Form of the Vineland Adaptive Behavior Scales [20] are additional examples of questionnaires that support a family-based collaborative assessment process. Both forms are completed through a semi-structured interview conducted by a trained and experienced professional. Open-ended questions, with suggested probes, allow parents or caregivers to describe their child's skills and abilities in their own words. Parent input is then used by the professional to score the Survey and/or Expanded Form.

A final example of a collaborative assessment process includes the use of the Social Emotional Assessment Measure (SEAM) [23-25], an assessment that gathers functional information from parents and other child-care personnel of children from 1 month to 5 $1 / 2$ years of age. Social and emotional strengths and needs of children are identified by the SEAM, and goals and objectives are then targeted to generate intervention content for positive behavioral supports for both the child and family. In addition to the assessment component, the SEAM Caregiver component assists in identifying information and resources that will help the parent to support their child's social and emotional development. Sample items from the Infant and Preschool Intervals, and SEAM Caregiver can be found in Table 1. Although the SEAM is a newly developed tool with few published studies to date, initial psychometric data are promising. Test-retest reliability for parents completing two SEAM questionnaires on their child was .95 for the Infant interval $(N=78$; $<$ < $.01)$ and .88 for the Toddler interval $(N=88 ; p<.01)$. Interrater reliability ranged from .60 (Infant Interval) to .74 (Toddler Interval) between questionnaires completed by preschool teachers and parents $(\mathrm{N}=29)$. Concurrent validity was also investigated, using the Infant Toddler Social Emotional Assessment (ITSEA)25. For the ITSEA Competence subscale, agreement with the SEAM Infant Interval was .64 $(\mathrm{N}=$ $24 ; p<.01)$ and with the Toddler Interval was $.59(\mathrm{~N}=$ 91; $\mathrm{N}=24 ; \mathrm{p}<.01)$. For the ITSEA Pro-social subscale, agreement with the SEAM .70 and .60 respectively $(p<.01)$. Finally, parents and practitioners rated the SEAM as having high utility and as assisting with structuring discussions and targeting goals for skills related to behavior and social emotional competence [24]. The SEAM was designed for use in a three-tier prevention model with strong parental collaboration, and is described further below.

In summary, questionnaires that elicit parental assessment of their child's development are a crucial component of collaborative, family-centered

Table 1: Sample SEAM Child and Caregiver Items: Infant and Preschool-Age Intervals

\begin{tabular}{|c|c|c|}
\hline Infant Interval & $\begin{array}{l}\text { C-1.0. BABY PARTICIPATES IN HEALTHY INTERACTIONS. } \\
\text { 1.1. Baby shows interest in you and other familiar caregivers. } \\
\text { - } \quad \text { Some examples might be: } \\
\text { - } \quad \text { Follows you with his eyes } \\
\text { - } \quad \text { Quiets when talked to } \\
\text { - } \quad \text { Looks at you when touched } \\
\text { - Shows pleasure when you return } \\
\text { - Seeks the attention of you or other familiar caregivers }\end{array}$ & $\begin{array}{l}\text { A-1.0. RESPONDING TO MY BABY'S NEEDS. } \\
\text { I understand my baby's nonverbal. } \\
\text { - Some examples might be: } \\
\text { - When my baby looks or smiles at me it } \\
\text { usually means that she is ready to play. } \\
\text { - When my baby is squirmy I know that he } \\
\text { has had enough to eat. } \\
\text { Please give examples of your baby's nonverbal } \\
\text { communication and ways that you respond: }\end{array}$ \\
\hline $\begin{array}{l}\text { Preschool- } \\
\text { Age Interval }\end{array}$ & $\begin{array}{l}\text { C-2.0. CHILD EXPRESSES A RANGE OF EMOTIONS. } \\
\text { 2.1. Child smiles and laughs. } \\
\text { Some examples might be: } \\
\text { - Laughs when another child makes a funny face } \\
\text { - Smiles when you come to pick her up from child care } \\
\text { - Smiles and laughs when playing with peers }\end{array}$ & $\begin{array}{l}\text { A-3.0. PROVIDING PREDICTABLE SCHEDULE/ } \\
\text { ROUTINES FOR MY CHILD. } \\
\text { 3.1. I provide a mealtime routine for my child that is } \\
\text { predictable and appropriate for his age. } \\
\text { Some examples might be: } \\
\text { - I provide my child with meals and snacks } \\
\quad \text { at regular times each day. } \\
\text { - I include my child in meal preparation } \\
\quad \text { when possible, such as grocery shopping, } \\
\text { picking out new vegetables, and } \\
\text { measuring and stirring. }\end{array}$ \\
\hline
\end{tabular}


approaches. When the AEPS Family Report asks parents, "What skills would you like your child to learn to help him or her participate more fully in family activities," parents are invited to be both co-assessors of their child's skills and collaborators in developing individualized and family-centered interventions. Such questions help facilitate authentic assessments which include the observations of the "familiar and knowledgeable" caregivers who know children the best [25].

\section{TIERED APPROACHES}

Many programs struggle to implement assessment strategies that involve families in meaningful ways, and that include cohesive links to services the child and family receive. Families and children need a coordinated and seamless assessment as well as an intervention process in which cognitive and other developmental needs are addressed in a timely and effective manner, using research-based assessment practices [6, 26]. One effective approach to include parents in a strategic and coordinated way is through the use of multiple tiers, or levels, of intensity of instruction that depend upon child and family needs $[27,28]$. The tiered approach stems from Response to Intervention (Rtl), a decision-making process designed to prevent delays in learning and behavior [29]. RtI involves a three-tiered model for instruction, embedded in a prevention framework. Tier 1 focuses on universal curriculum aimed at all children, while Tier 2 practices provide targeted group instruction for children who need it. Tier 3 provides more intensive, individualized instruction for children who require support beyond the practices implemented in Tier 1 and Tier 2.

A major benefit of an Rtl approach is access to a continuum of services, including those involving family members at all levels. Before Rtl models, children needed a comprehensive eligibility assessment to receive individualized instructional programs for remediation of delays and often spent unproductive weeks in large instructional groups with little or no learning taking place. No longer do programs have to wait for children to fail, or show a significant delay in order to provide services.

Universal screening is an inherent feature of Tier 1 , while continuous progress monitoring and databased decision making are integral features in Tiers 2 and 3. However, Rtl provides no clear guidelines for the specific types of assessments to be used for monitoring and making decisions in Tiers 2 and 3 , nor the specific role of families. Family-centered assessment practices can be implemented in each of the tiers to provide evidence for decisions about needed services and interventions. The child can move across tiers if needs develop, as illustrated in Figure 1.

\section{The Most Useful Family Assessments will Tie Directly to Intervention and Program Evaluation $[24,30]$}

This quote highlights the necessary relationship between contributions of the family and the tiered

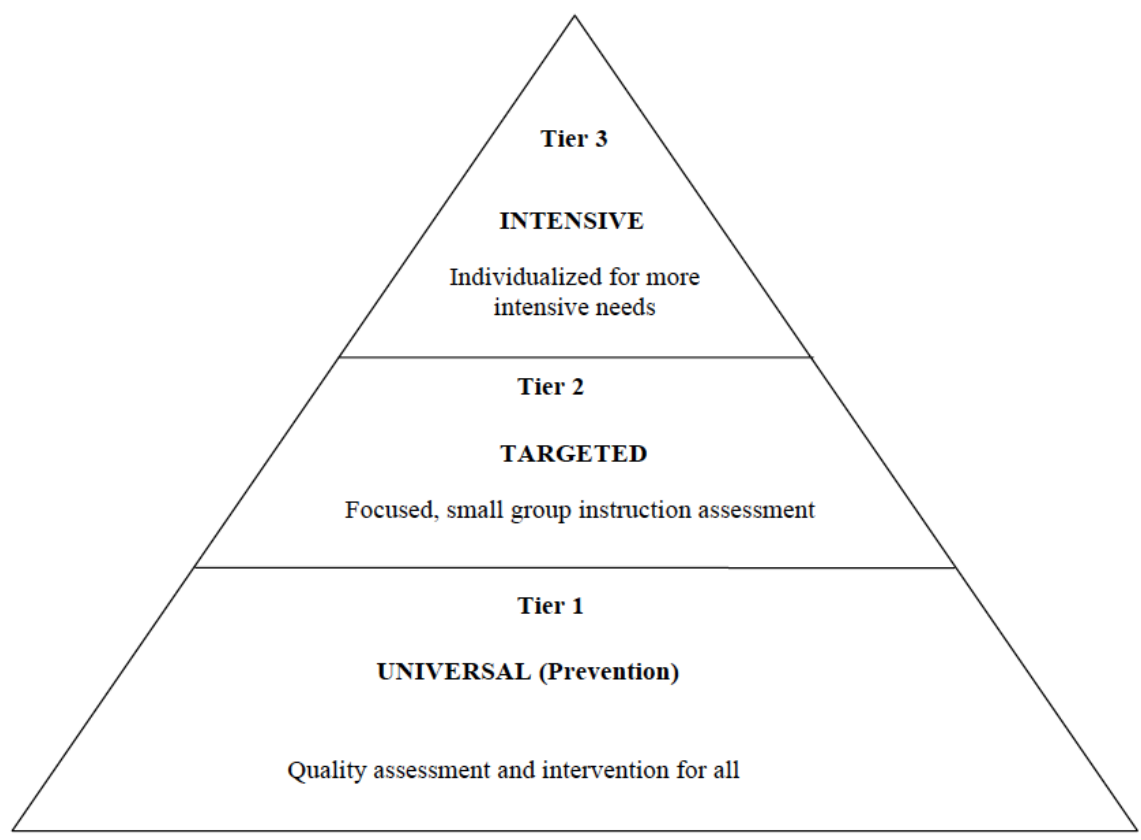

Figure 1: Tiered approach. 


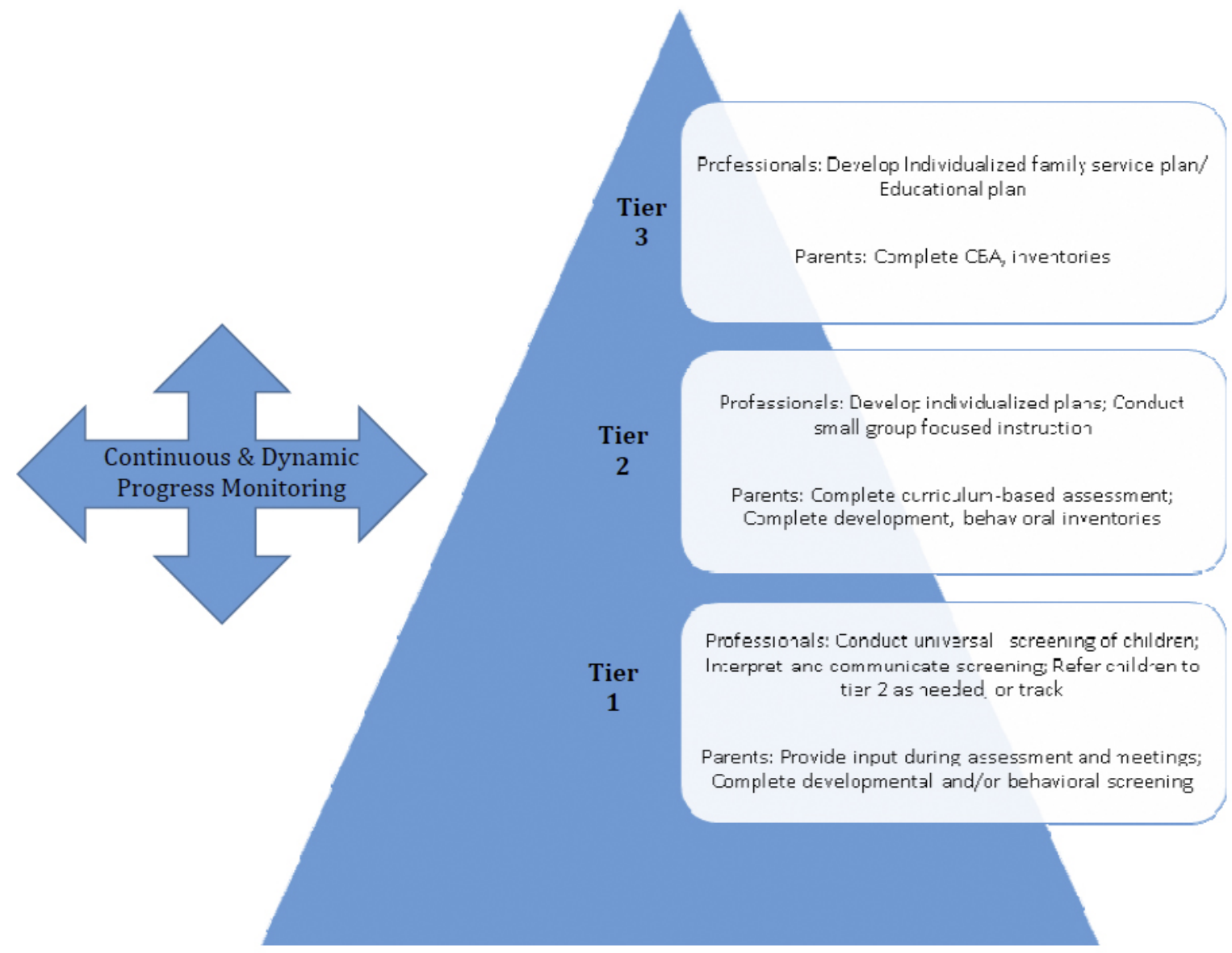

Figure 2: Professional and parent roles in a tiered approach.

system created for children and their families. In each tier, parents have an opportunity to provide additional information about skills they would like their child to learn [31]. Roles that parents and professionals might play in each tier are outlined in Figure 2.

\section{Tier 1}

Tier 1 assessment practices are aimed at all children in an early childhood program, where the goal is the enhancement of developmental skills and the prevention of learning problems and/or developmental delays. Universal screening of all children is a first tier practice that seeks to identify children early on who may have, or be at-risk for developing problems. In Tier 1, parent-completed developmental screening questionnaires allow all parents to provide input about their child's development as well as family concerns and needs. This input is essential for identifying children who need more comprehensive evaluation and/or additional interventions. Parents can provide additional information about family context (cultural values, family constellation) that is critical to the screening process [32].

\section{Tier 2}

The research-based early childhood curricular content, universal screening, and teaching practices used in Tier 1 may not be adequate to meet the needs of all children. When children who need additional services for cognitive and other delays are identified through collaborative assessment practices such as parent-completed screening tests, Tier 2 practices are implemented. In a Tier 2 assessment process, professionals engage parents and family members in direct observation of their child, including assisting with completion of curriculum-based measures. As coassessors, parents provide important information about the developmental strengths they see their child displaying in familiar routines and natural environments, as well as about areas of need. This input helps to inform planning of interventions and learning activities that address educational and/or developmental needs. Interventions in Tier 2 can be outlined in individual or group plans and embedded into small group, classroom-based activities. The child's team (i.e., parents and professionals) can monitor 
progress toward goals and make adjustments when necessary.

If the child responds positively to Tier 2 supports/services, she or he may no longer need them and will then continue to receive the general early childhood care and education program for the majority of children, characterized by Tier 1 . If the child does not respond to Tier 2 supports/services, then the team will need to consider Tier 3 approaches.

\section{Tier 3}

Tier 3 practices are available for children who may require intensive interventions unique to their needs. As in Tier 2, professionals work closely with parents to gather additional assessment information in order to identify child and family goals, objectives, and family outcomes. These in turn guide the development of evidence-based intervention practices specifically designed for individual children and families. Without family participation in this assessment process, identified goals may not address areas most important to the family and relevant to the child.

\section{Family-Centered Assessment in the Social Emotional Realm}

The attempts of early child programs to address the social emotional needs of young children illustrate the important role of family and professional collaboration in the assessment process. Early childhood providers often are limited in their ability to effectively assess and intervene with challenging behaviors. As a result, preschoolers are being excluded from school at an alarming rate [33]. For timely identification and effective intervention, personnel need behavioral measures and procedures that yield reliable information about social emotional strengths and needs (current repertoire), and that track change over time (progress monitoring). Furthermore, personnel need information from the family about supports needed to enhance the child's social emotional development.

The Social Emotional Assessment Measure (SEAM), described earlier, is an example of an assessment that gathers functional information from teachers and other child-care personnel and was developed to be used in a three-tier prevention model. In a three-tier model, universal screening using a tool such as the Ages \& Stages Questionnaires: Social Emotional (ASQ:SE) [7] or Brief Infant Toddler Social Emotional Assessment (BITSEA) [21] can be conducted in the first tier. The question to be answered by universal screening is: Is the child developing on a typical trajectory? Or Does he/she need more comprehensive assessment? Based on the results of these assessments, the child may move to Tier 2 where she will receive more targeted assessments and interventions, or to Tier 3 , where she will receive individualized, targeted interventions. The following scenario illustrates how parents and teachers collaborate in the assessment and intervention process within a tiered model.

Sunshine Center is a neighborhood early childcare facility that supports the education and general development of toddler-age children. The mission of Sunshine includes a commitment to helping children develop positive social and emotional competence skills. In support of this mission, all parents complete a social-emotional screening tool-the Ages and Stages Questionnaires: Social Emotional (ASQ$S E$ - -at regular intervals while their children are enrolled at Sunshine. When Maria and Samuel come to enroll their two-year-old daughter, Rose, Teacher Melissa describes the ASQ-SE and asks them to complete this social-emotional screening questionnaire. Maria and Samuel decide to complete the questionnaire on their own at home. During their next visit to Sunshine, Teacher Melissa reviews the completed ASQ:SE with them and learns that they have some concerns about Rose's ability to calm herself down and to fall asleep. In addition, Rose's ASQ:SE score falls just above the cutoff, indicating a potential need for more evaluation. Selected items from Rose's ASQ:SE and the ASQ:SE scoring cutoff grid can be seen in Figure 3.

For children such as Rose who need more targeted interventions, the SEAM can then be used to gather additional information about the child's specific strengths as well as the social emotional skills the child needs support in developing. Family needs and desires regarding their child's behavior can also be elicited through the use of the SEAM. Parents respond to the age-appropriate SEAM items, indicating whether their child has specific skills, such as "expresses a range of emotions" and "can calm self when upset." Parents can also indicate whether this skill (or lack of skill) is a 
Type of

Assessment

Answers this Question

Collaborative Family Roles
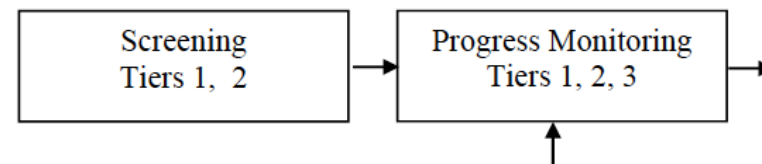

Is the child making progress?

developmental, or behavioral problem/issue?

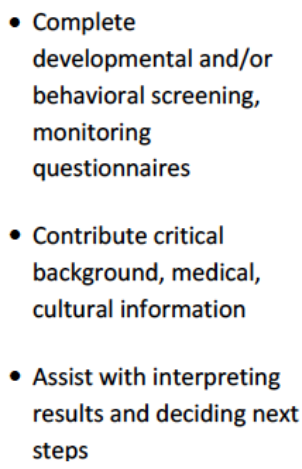

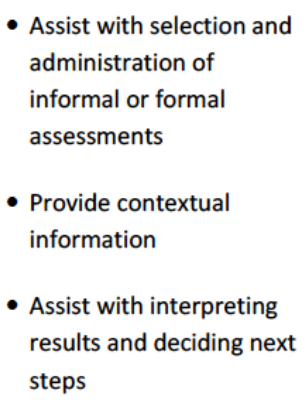

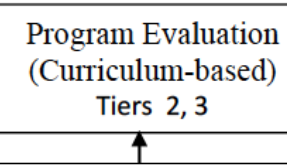

What is the level of progress towards group and/or individual goals? extent of the problem/issue?

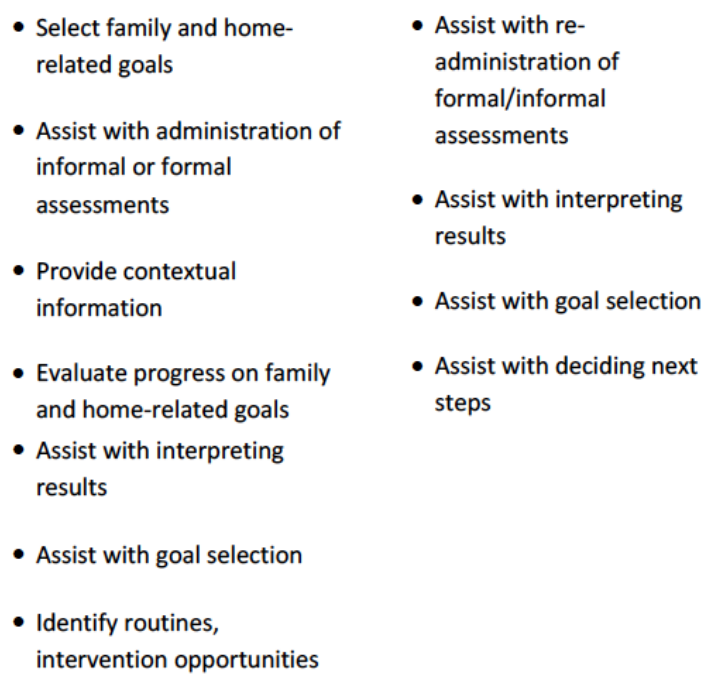

Figure 3: Selected items and scoring grid from Rose's 24 month ASQ:SE.

concern to them, and whether they would like to target this skill as an intervention goal. The question to be answered in Tier 2 is: What specific supports and services are needed to address areas of developmental need? The results of the SEAM assessment can be used in Tier 2 to develop learning and development goals for the child as well as the family, and identified social and emotional skills and behaviors can then be addressed in small group instruction. Activity and routines-based interventions are then developed to work on the areas of need. Parents can assist with re-administration of the SEAM to evaluate progress toward established goals.

In order to get a more comprehensive picture of Rose's social and emotional skills, Teacher Melissa suggests using the Toddler interval of the SEAM to gather additional information from Maria and Samuel. They agree, and Teacher Melissa presents SEAM items in an interview format, while Maria and Samuel read along from their own copy of the SEAM protocol. In conversation with Teacher Melissa, Maria and Samuel can indicate whether Rose performs each skill consistently. For example, when Teacher
Melissa asks about Rose's ability "to settle herself down after periods of exciting activity," Maria describes the family ritual of after-dinner playtime, when Rose and Samuel wrestle and play Chase together. Even though this activity takes place hours before bedtime, Rose often has great difficulty calming down afterward and going to sleep. Bedtime has become a long, drawn-out, and frustrating process. When asked whether this is a concern, Rose's parents say that it is, and that they want to know how to help Rose calm down. Together, Teacher Melissa and Rose's parents agree to focus on this intervention goal. Teacher Melissa agrees to provide classroom strategies that help Rose and all children in her classroom to calm down after exciting activities and transition into new ones. They also come up with some strategies for Maria and Samuel to implement at home to help Rose get to sleep at night.

During the three months following her initial meeting with Rose's parents, Teacher Melissa uses the SEAM to 
monitor their selected goals. Maria and Samuel also monitor Rose's progress at home. After the 3 months have passed, Teacher Melissa and Rose's parents sit down and review the SEAM. While Rose's ability to calm down before bed has improved somewhat, Samuel indicates that Rose doesn't consistently "accept changes in routines and settings." In fact, Rose often cries and becomes frustrated when asked to stop one activity and begin another at home. For example, it is very difficult to leave the house to go somewhere, and Rose's parents don't understand what she wants and why she is upset. Teacher Melissa has also noticed that Rose continues to struggle with transitions between classroom activities. Maria and Samuel indicate that they would like to keep working on Rose's ability to calm herself and to make transitions. Together, Maria, Samuel and Teacher Melissa work on a plan to address these concerns. Teacher Melissa tells Maria and Samuel about their local early intervention services agency, and they agree that they would like to gather additional information in order to get a better understanding of Rose's behaviors.

When, like Rose, a child does not respond to the group interventions initiated in Tier 2, the assessment team may decide to try more individualized approaches in Tier 3. As in Tier 2, parents can assist with completion of a curriculum-based measure such as the SEAM or AEPS, to be used in Tier 3 as an assessment to corroborate eligibility information gathered from standardized, norm-referenced tests. Some questions to be answered in Tier 3 are: (a) Is the child eligible for specialized services, and (b) What specific, individualized supports and services are needed?

Rose's parents contact their local early intervention program, where Rose is assessed using the Vineland, described earlier, along with the Communication and Symbolic Behavior Scale (CSBS), a normreferenced, standardized instrument used to assess infants, toddlers, and preschoolers at risk for communication delays and impairments. Rose is found eligible for services in the social-emotional and communication areas, and an IFSP is developed using information from both of these tests as well as input gathered from Maria and Samuel through the SEAM. As a result of this process, a speech language pathologist begins providing individualized Tier 3 services to Rose both at home and at Sunshine, focusing on her communication skills and ability to transition between activities. Rose remains in her small instructional group (Tier 2), where Teacher Melissa focuses on communication and social emotional skill building with her class. At their next meeting, Maria and Samuel thank Teacher Melissa for acknowledging their concerns, validating their feelings, and working on these issues together. They express their enthusiasm about the additional services and their hope that Rose will be less frustrated and more able to communicate with them about her wants and needs.

\section{RECOMMENDATIONS}

A comprehensive model of assessment and intervention, with family input in each phase, is recommended for family-professional collaboration in assessment of preschool children with disabilities, as shown in Figure 4. Universal developmental screening of young children should be conducted in physician's offices and daycare/preschool settings, as well as in programs serving young children and families such as WIC. Using parent-completed screening assessments such as the BITSEA [21] and the Ages and Stages Questionnaires [23] is a recommended strategy, both by medical $[34,35]$ and early childhood professional organizations $[6,36]$.

During the programmatic assessment and evaluation phases, parental involvement and input are essential to accurately identify the full range of a child's skills and interests, as well as the circumstances in which behavioral and developmental issues arise, and to assess how these impact both the child and family. Parents are also crucial partners in identifying interventions that are meaningful and motivating for their children, and in providing interventions in the child's natural environment. Identifying family routines and opportunities for embedding learning opportunities are critical components of effective intervention planning. Assessments that include components focused on children's skills as well as parents' resources and needs help providers to match specific 


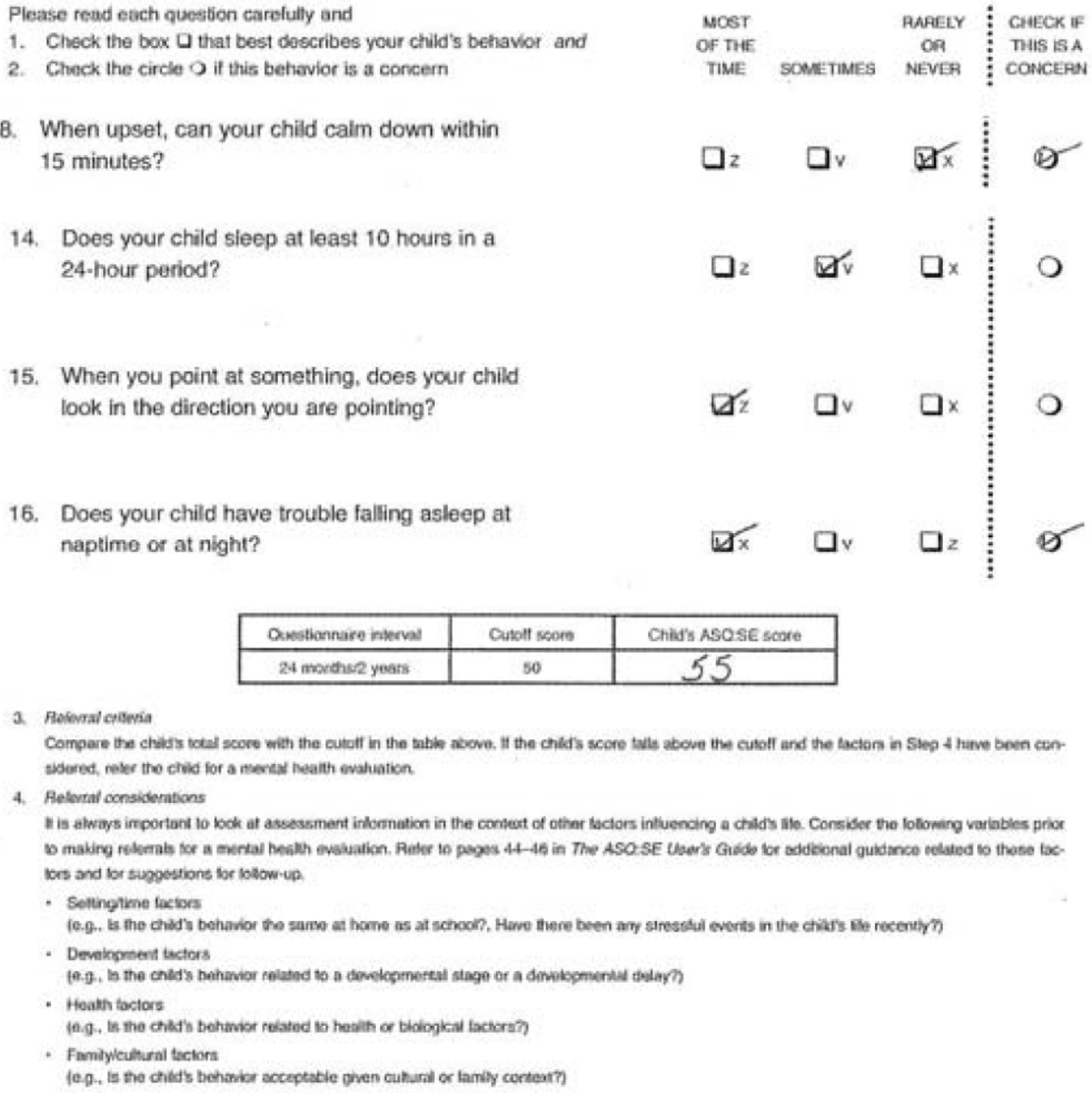

Figure 4: Collaborative family and professional roles in assessment.

interventions to the level of support required by a particular family [37].

If a child moves to the eligibility phase, family members should be asked to participate in the formal assessment process, as facilitators and providers of vital information rounding out the circle of information gathered on the child's developmental and cognitive skills.. We believe that when parent-completed screening assessments indicate serious developmental and/or social-emotional delays, and parents and professionals share concerns about the child, that the eligibility phase can be streamlined or eliminated altogether and the child referred immediately to an El/ECSE program for special education services. A service-based approach to establishing eligibility for individualized Tier 3 services, including the supports the child may need to perform satisfactorily in the general preschool or kindergarten classroom, may be a more efficient and effective method than the traditional deficit-based diagnoses procedures used by many programs today [38].

\section{SUMMARY/CONCLUSIONS}

Family-centered assessment, similar to other familycentered practices, includes treating families with respect and dignity; individualizing practices to fit unique family needs; enabling families to make informed choices through information sharing; and actively involving family members in the mobilization of services and supports for their preschool children [39, 40] Parent and professional partnerships during the assessment process form the foundation for delivery of enriching, satisfying, and enhancing early childhood interventions for intellectual and other developmental delays.

Without this partnership in all levels and phases of the assessment process, inappropriate goals and strategies-based on erroneous information-may be targeted, leading to ineffective and potentially discordant intervention practices. Parent-completed developmental screening tests, and parent assistance with completion of curriculum-based assessments, are 
two strategies that have been shown to provide a common language for parent and professional communication and facilitation of cooperation between professionals and parents [23, 41]. Positive, strengthsbased assessments conducted in naturalistic environments by familiar adults and caregivers will also yield more reliable and valid results. Parents and professionals can work together to target and provide fun and valuable early activities for young preschool children with delays and disabilities that will lead to productive and successful experiences in school and community settings.

\section{REFERENCES}

[1] Bagnato S, Neisworth J. Assessment for early intervention: Best practices for professionals. The Guilford school practitioner series: NY 1991; pp. xi.

[2] Bagnato SJ, McKeating E, Bartolamasi A. Evidence-base for Team Assessment Practices in Early Intervention, Washington, DC-Pittsburgh, PA/Asheville, NC: TRACE Center for Excellence in Early Childhood Assessment, Puckett Institute, Early Childhood Partnerships, US Department of Education, Office of Special Education Programs (OSEP) 2007.

[3] Bagnato S, Smith-Jones J, Matesa M, McKeating-Esterle E. Research foundations for using clinical judgment (informed opinion) for early intervention eligibility determination. Cornerstones 2006; 3(2): 1-14.

[4] Finello K. Collaboration in the assessment and diagnosis of preschoolers: Challenges and opportunities. Psychol Schools 2011; 48(5): 442-53.

http://dx.doi.org/10.1002/pits.20566

[5] Odom S, Wolery M. A unified theory of practice in early intervention/early childhood special education. J Special Educ 2003; 37: 164-73.

http://dx.doi.org/10.1177/00224669030370030601

[6] Sandall S, Hemmeter ML, Smith BJ, McLean ME. DEC recommended practices: A comprehensive guide for practical application in early intervention/early childhood special education. Longmont: Sopris West 2005.

[7] Squires J, Twombly E, Bricker D, Potter L. Ages and stages questionnaires (ASQ): A parent-completed child monitoring system (3rd ed.). Baltimore: Brookes 2009.

[8] Trivette C, Dunst C. DEC recommended practices: Familybased practices. In Sandall S, Hemmeter M, Smith B, McLean M, Eds. DEC recommended practices: A comprehensive guide for practical application in early intervention/early childhood special education. Missoula, MT: Division of Early Childhood 2005; pp. 107-126.

[9] Hagie M, Gallipo P, Svien L. Traditional culture versus traditional assessment for American Indian students: An investigation of potential test item basis. Assessment Effective Interven 2003; 23(1): 15-25. http://dx.doi.org/10.1177/073724770302900103

[10] Neisworth J, Bagnato S. The mismeasure of young children: The authentic assessment alternative. Infants Young Child 2004; 17(3): 198-12.

http://dx.doi.org/10.1097/00001163-200407000-00002

[11] Division of Early Childhood (DEC). Responsiveness to ALL children, families, and professionals: Integrating cultural and linguistic diversity into policy and practice. DEC Position Statement. Missoula, MT: Division for Early Childhood 2010.

[12] Sandall M, McLean M, Smith B. Eds. DEC's Recommended Practices for Early Intervention and Early Childhood Special Education. Longmont, CO: Sopris West 2010.
[13] Division for Early Childhood (DEC). Promoting positive outcomes for children with disabilities: Recommendations for curriculum, assessment, and program evaluation. Missoula, MT: Author 2007.

[14] Copple C, Bredekamp S. Developmentally appropriate practice in early childhood programs: Serving children from birth through age 8. Washington, DC: National Association for the Education of Young Children 2009.

[15] Snow C, Van Hemel S. Early childhood assessment: Why, what, and how. Washington, D.C.: The National Academies Press 2008.

[16] Frankenburg W, VanDoorninck W, Liddell T, Dick N. The Denver Prescreening Developmental Questionnaire (PDQ). Pediatrics 1976; 57: 744-53.

[17] Frankenburg W, Dodds J. The Denver Developmental Screening Test. J Pediatr 1967; 71(181). http://dx.doi.org/10.1016/S0022-3476(67)80070-2

[18] Achenbach T. Child behavior checklist/2-3 years (CBCL/2-3). Burlington, VT: University of Vermont Department of Psychiatry 1991.

[19] Bayley N. Bayley Scales of Infant Development (BSID-II). San Antonio, TX: The Psychological Corporation 2006.

[20] Sparrow S, Balla D, Cicchetti D. Vineland Social-Emotional Early Childhood Scales. Circle Pines, MN: American Guidance Service 1998.

[21] Briggs Gowan M, Carter A. The Brief Infant-Toddler Social and Emotional Assessment (BITSEA). San Antonio, TX: Psychological Corporation, Harcourt Assessment 2005.

[22] Bricker D. Assessment, evaluation, and programming system for infants and children: Volumes 1-4 administration guide ( $2^{\text {nd }}$ ed.). Baltimore: Paul Brookes 2002.

[23] Squires J, Bricker D. Ages and stages questionnaires $3^{\text {rd }}$ edition: A parent-completed child-monitoring system. Baltimore, MD: Brookes Publishing 2009.

[24] Squires J, Waddell M, Clifford J, Funk M, Hoselton R, Chen C. Psychometric study of the infant and toddler intervals of the social emotional assessment measure. Top Early Childhood Special Educ 2013; 33(2): 78-90. http://dx.doi.org/10.1177/0271121412463445

[25] Bagnato S, Yeh-Ho H. High-stakes testing with preschool children: Violation of professional standards for evidencebased practice in early childhood intervention. KEDI Int $\mathrm{J}$ Educat Policy 2006; 3(1).

[26] VanDerHeyden AM, Snyder PS. Integrating frameworks from early childhood intervention and school psychology to accelerate growth for young children. School Psychol Rev 2006; 35(4): 519-34.

[27] Brown-Chidsey R, Steege MW. Response to intervention: Principles and strategies for effective practice. New York: Guildford Press 2005.

[28] Stecker PM. Tertiary intervention: Using progress monitoring with intensive services. Teach Except Child 2007; 39(5): 5057.

[29] Fox L, Carta J, Strain P, Dunlap G, Hemmeter ML. Response to Intervention and the Pyramid Model. Tampa, Florida: University of South Florida, Technical Assistance Center on Social Emotional Intervention for Young Children 2009.

[30] Slentz KL, Bricker D. Family-guided assessment for IFSP development: Jumping off the family assessment bandwagon. J Early Interven 1992; 16(1): 11-19. http://dx.doi.org/10.1177/105381519201600102

[31] Byrd ES. Educating and involving parents in the response to intervention process: The school's important role. Teach Except Child 2011; 43(3): 32-39.

[32] Fiese BH, Spagnola M, Everhart RS. Family context in developmental-behavioral pediatrics. In Wolraich M, Dworkin P, Drotar D, Perrin E, Eds. Developmental-behavioral 
pediatrics: Evidence and practice. Philadelphia: Elsevier 2008 ; p. 79.

http://dx.doi.org/10.1016/B978-0-323-04025-9.50008-8

[33] Gilliam W, Shabar G. Preschool and child care expulsion and suspension rates and predictors in one state. Infants Young Child 2006; 19(3): 228-45.

http://dx.doi.org/10.1097/00001163-200607000-00007

[34] American Academy of Pediatrics. Recommendations for preventive pediatric health care. Pediatrics 2007; 120(6): 1376. http://dx.doi.org/10.1542/peds.2007-2901

[35] American Academy of Pediatrics. Reaffirmed policy statement-- pediatric primary health care. Pediatrics 2011; 127(2): 397.

http://dx.doi.org/10.1542/peds.2010-3416

[36] Henderson J, Strain P. Screening for social emotional concerns: Considerations in the selection of instruments. Tampa, FL: University of South Florida 2009.

[37] Powell D, Dunlap G. Family-focused interventions for promoting social-emotional development in infants and toddlers with or at risk for disabilities. Roadmap to Effective Intervention Practices \#5. Tampa, FL: University of South Florida, Technical Assistance Center on Social Emotional Intervention for Young Children 2010.

[38] Bagnato S, Neisworth J, Pretti-Frontczak K. LINKing authentic assessment and early childhood intervention: Best measures for best practices (4th Edition). Baltimore, MD: Paul Brookes Publishing Co., Inc. 2010.

[39] Dempsey I, Keen D. A review of processes and outcomes in family-centered services for children with a disability. Top Early Childhood Special Educ 2008; 28: 42-52. http://dx.doi.org/10.1177/0271121408316699

[40] Dunst C, Trivette C, Hamby D. Research synthesis and meta-analysis of studies of family-centered practices (Winterberry Press Monograph Series). Asheville, NC: Winterberry Press 2008.

[41] Squires J, Bricker D. An activity-based approach to developing young children's social emotional competence. Baltimore: Brookes 2007.

\section{DOI: http://dx.doi.org/10.6000/2292-2598.2013.01.01.9}

\section{(C) 2013 Squires et al.; Licensee Lifescience Global.}

This is an open access article licensed under the terms of the Creative Commons Attribution Non-Commercial License (http://creativecommons.org/licenses/by-nc/3.0/) which permits unrestricted, non-commercial use, distribution and reproduction in any medium, provided the work is properly cited. 